\section{P131 MYOCARDIAL INJURY AND DYSFUNCTION DURING COPD EXACERBATIONS}

ARC Patel, BS Kowlessar, GC Donaldson, AJ Mackay, R Singh, JA Wedzicha, JR Hurst; University College London, London, UK

\subsection{6/thoraxjnl-2013-204457.281}

Introduction Cardiac biomarkers of myocardial injury and dysfunction are commonly raised in patients hospitalised with COPD exacerbations and are independent predictors of mortality. The relevance of this to the majority of community-treated events has not previously been studied.

Methods We prospectively measured serum troponin $\mathrm{T}$ and $\mathrm{N}-$ terminal brain pro-natriuretic peptide (NT-proBNP) in 55 patients from the London COPD Cohort in the stable state, at exacerbation onset and thereafter at days $3(\mathrm{n}=44), 7$ $(\mathrm{n}=39), 14(\mathrm{n}=38)$, and $35(\mathrm{n}=25)$ during recovery. Exacerbation assessments were undertaken within one week of symptom onset, prior to therapy, and defined by two consecutive days of new or increased respiratory symptoms on prospectivelycompleted daily patient diary cards requiring at least one major (dyspnoea, sputum purulence, sputum volume) and another major or minor symptom (coryza, wheeze, sore throat and cough).

Results Cardiac biomarkers rose from the stable state to exacerbation (mean $( \pm \mathrm{SD}$ ) troponin T $0.012( \pm 0.011)$ vs 0.017 $( \pm 0.016) \mu \mathrm{g} / \mathrm{L}, \mathrm{p}<0.001$; NT-proBNP 23.1 ( \pm 39.2$)$ vs 36.0 $( \pm 56.5) \mathrm{pg} / \mathrm{ml}, \mathrm{p}<0.001)$. These increases were significantly higher in those with known IHD $(\mathrm{n}=12)$ compared to those without IHD $(n=43)$ (mean $( \pm S D)$ increase in troponin $T$ $0.011( \pm 0.009)$ vs $0.003( \pm 0.006) \mu \mathrm{g} / \mathrm{L}, \mathrm{p}=0.003$; NTproBNP $38.1( \pm 37.7)$ vs $5.9( \pm 12.3) \mathrm{pg} / \mathrm{ml}, \mathrm{p}<0.001)$.

Cardiac biomarkers did not fall during the initial five-week exacerbation recovery period (troponin $\mathrm{T}-0.0003 \mu \mathrm{g} / \mathrm{L} /$ day $(95 \%$ CI -0.0008 to 0.0004$), p=0.431$; NT-proBNP $-0.096 \mathrm{pg} / \mathrm{ml} /$
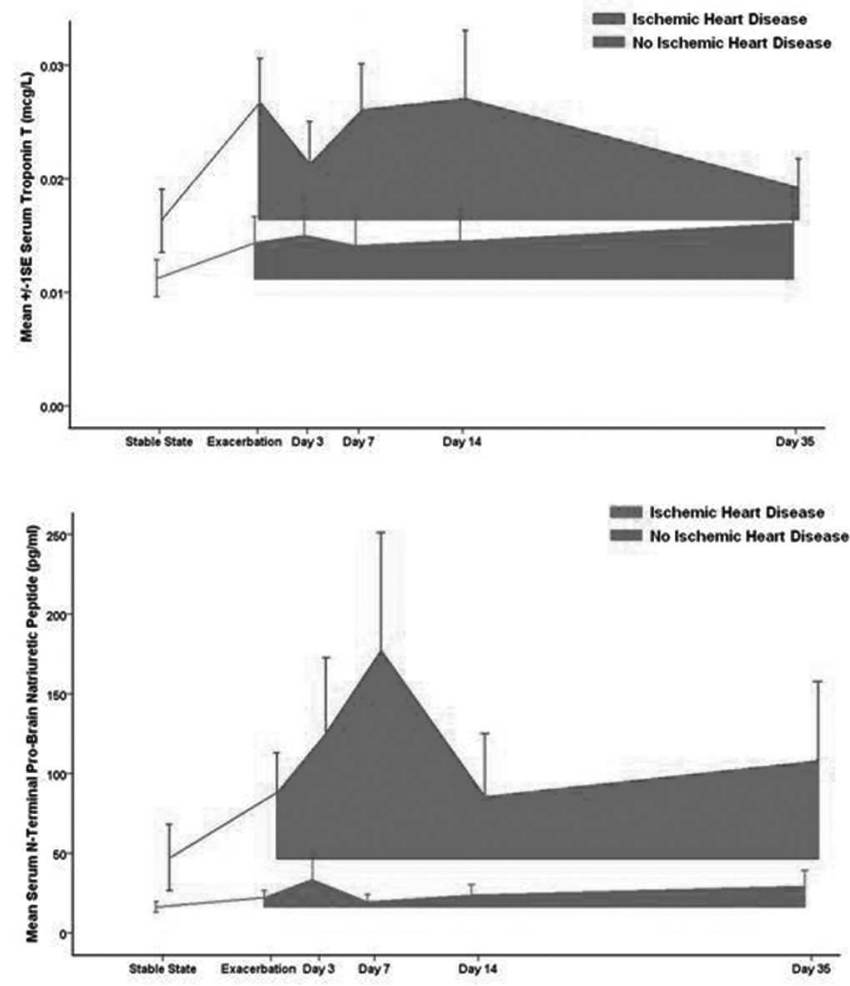

Abstract P131 Figure 1. day (95\% CI -0.631 to 0.438$), p=0.723)$. They remained more elevated in those with IHD $(n=12)$ than in those without IHD $(\mathrm{n}=43)$ during the five week recovery period (troponin T AUC $0.368 \pm 0.311 \mu \mathrm{g} / \mathrm{L} / 35$ days vs $0.088 \pm 0.174 \mu \mathrm{g} / \mathrm{L} /$ 35days, $\mathrm{p}<0.001$; NT-proBNP AUC $1590 \pm 2620 \mathrm{pg} / \mathrm{ml} /$ 35 days vs $279 \pm 725 \mathrm{pg} / \mathrm{ml} / 35$ days, $\mathrm{p}=0.005$ ).

Longer exacerbations were associated with greater myocardial injury at exacerbation (higher serum troponin $\mathrm{T}$ ) and the magnitude of change from the stable state ( $\mathrm{rho}=0.323, \mathrm{p}=0.027$; rho $=0.390, \mathrm{p}=0.007$ respectively).

Conclusions Myocardial injury and dysfunction is common and clinically significant during COPD exacerbations in those with underlying IHD and relates to exacerbation length. Alternative approaches to mitigate cardiovascular complications, in stable COPD and at exacerbation, require further study.

\section{P132 LACK OF CHANGE IN OUTCOMES ACCOMPANYING SIGNIFICANT IMPROVEMENT IN CLINICAL PARAMETERS OF CARE OF PATIENTS ADMITTED WITH COMMUNITY ACQUIRED PNEUMONIA}

${ }^{1} \mathrm{IJ}$ Maxwell, ${ }^{2} \mathrm{~S}$ Merritt, ${ }^{2}$ OK Kankam, ${ }^{1} \mathrm{DL}$ Maxwell; ${ }^{1}$ Eastbourne DGH, East Sussex NHS Healthcare Trust, Eastbourne, United Kingdom; ${ }^{2}$ Conquest Hospital, East Sussex NHS Healthcare Trust, Eastbourne, United Kingdom

\subsection{6/thoraxjnl-2013-204457.282}

Background Significant improvements in quality of inpatient care would be expected to improve objective outcomes, such as length of stay (LOS) and mortality. The management of community acquired pneumonia was reviewed on both sites of this Trust over a 33 month period during which time training and feedback was provided on management, monitoring 5 aspects of clinical care:- documentation of oxygenation; documentation of CURB65 scores; blood cultures (if obtained) taken before antibiotics; antibiotics given in accordance with Trust guidelines; antibiotics given within 6 hrs.

Methods 4922 patients discharged between July 2010 and March 2013 had been coded as being admitted with pneumonia. The notes of 52 patients were unobtainable. Patients were excluded where there was no evidence of pneumonia on admission CXR, where the admitting clinicians had not diagnosed pneumonia or when the pneumonia was not considered to be community acquired. A monthly 'composite quality score' (CQS) score was derived by averaging the percentage of the 5 parameters that were achieved for each patient/admission.

Results 2842 (58\%) patients remained for analysis. Significant improvements were noted in all the parameters being monitored with quarterly CQS scores rising from $68 \%$ to $93 \%$ and, more specifically, quarterly scores for antibiotic delivery within 6 hrs increasing from $40 \%$ to $78 \%$. Despite this no improvement at all was seen in LOS (quarterly LOS range: 10.8-13.4 days; no time trend). A gradual fall in mortality occurred, but only at one of the two sites (absolute fall of $2.8 \%$ per yr cf. no change). Of note was an unexpected and progressive increase in quarterly admissions (35\% per year) at the site with falling mortality, but no change at the other.

Conclusions Demonstrable improvement in parameters of clinical care result from education and feedback. However, a subsequent lack of change in outcomes (LOS, and, at one site, in mortality) despite such clear improvements would be unexpected. There may either be more appropriate clinical parameters on which to focus or these outcomes may have 